\title{
DETERMINAÇÃO DA QUANTIDADE DE DNA NUCLEAR EM PLANTAS
}

\author{
NUCLEAR DNA CONTENT DETERMINATION IN PLANTS
}

\author{
Maria Teresa Schifino-Wittmann ${ }^{1}$
}

- REVISÃO BIBLIOGRÁFICA -

RESUMO

\begin{abstract}
$O$ valor $C$ de DNA é um caráter de significado biológico fundamental e o conhecimento da quantidade de DNA nuclear de um grupo de organismos pode ser útil em vários campos da ciência. Do ponto de vista prático, a determinação da quantidade de DNA nuclear, que é mais comumente realizada por microdensitometria de Feulgen e citometria de fluxo, pode substituir a contagem de cromossomos, especialmente quando se trabalha com um número muito grande de indivíduos. A microdensitometria por Feulgen baseia-se na ligação específica do DNA a esse corante, havendo uma proporcionalidade entre a quantidade de DNA existente e a quantidade de corante que o núcleo incorporou. A citometria de fluxo envolve a análise das propriedades óticas de partículas em fluxo. Em plantas, basicamente consiste no isolamento dos núcleos, coloração destes com um fluorocromo e leitura da fluorescência emitida. As grandes vantagens desta técnica, em relação à microdensitometria de Feulgen, são a relativa facilidade e a rapidez da preparação das amostras, o grande número de núcleos que podem ser analisados, a necessidade de pequenas quantidades de tecido e a possibilidade de detecção de pequenas diferenças na quantidade de DNA. Relatos de resultados conflitantes entre determinações de diferentes autores mostram a necessidade de uma criteriosa padronização das técnicas, para que problemas metodológicos não venham a ser interpretados como eventuais diferenças reais na quantidade de DNA.
\end{abstract}

Palavras-chave: quantidade de DNA nuclear, Feulgen, citometria de fluxo

\section{SUMMARY}

The DNA $C$ value is an important biological characteristic and the knowledge of DNA content may be applied to several branches of science. Nuclear DNA content determinations, normally performed by Feulgen microdensitometry and flow cytometry, may replace chromosome counts especially when a high number of individuals are being analysed. Feulgen microdensitometry is based on the affinity of this dye and the DNA: the amount of DNA is proportional to the amount of dye taken by the nucleus. Flow cytometry is based on the optical properties of particles on a flow. In plants the technique basically consists in the isolation of nuclei, staining with a fluorochrome and measurement of the emitted fluorescence. The advantages of this technique, when compared to Feulgen densitometry, are the relative easiness and speed of sample preparation, the possibility to analyse a high number of nuclei, the need of small tissue amounts and the detection of small differences in DNA contents. Conflicting results from different authors show the need of a rigid technical standardization so that methodological errors are not misinterpreted with eventual real differences in DNA contents.

Key words: nuclear DNA content, Feulgen, flow cytometry

\section{INTRODUÇÃO}

Sabe-se que a maior parte do DNA dos eucariotes está presente no núcleo das células e, em menor quantidade, em organelas como as mitocôndrias e os cloroplastos.

A quantidade de DNA nuclear de um dado organismo, normalmente referida como valor $\mathrm{C}$, referindo-se a letra $\mathrm{C}$ ao termo constante (BENNET \& LEITCH, 1995), expressa o tamanho do genoma, ou seja, quantidade de material genético existente. A quantidade de DNA nuclear tem signifi-

\footnotetext{
${ }^{1}$ Biólogo, Professor Adjunto, Doutor, Departamento de Plantas Forrageiras e Agrometeorologia, Faculdade de Agronomia, Universidade Federal do Rio Grande do Sul. CP 776, 91501-970, Porto Alegre, RS, Brasil. Bolsista do CNPq. E-mail: mtschif@ vortex.ufrgs.br.
} Recebido para publicação em 11.07.00. Aprovado em 06.12.00 
cado adaptativo e influencia o fenótipo de duas maneiras distintas, ou seja, pela expressão de seu conteúdo e pelos seus efeitos físicos. O termo nucleotipo refere-se aos aspectos do DNA nuclear que afetam o fenótipo independentemente da informação contida (BENNET, 1971, BENNET, 1972)

Nesta revisão, serão abordados e discutidos alguns aspectos das técnicas de determinação de DNA nuclear em plantas, suas aplicações, vantagens e desvantagens.

\section{CONSIDERAÇÕES GERAIS}

Ao longo das grandes linhas evolutivas, há uma relação geral entre aumento da quantidade de DNA e complexidade evolutiva. Porém, a descoberta de que essa quantidade varia em até $80 \mathrm{mil}$ vezes entre os eucariotes e que esta variação não está necessariamente relacionada com o número de genes nem com a complexidade dos organismos, levou a formulação do conceito de paradoxo $\mathrm{C}$, ou seja, por que alguns organismos possuem muito mais DNA do que outros de igual ou superior posição na escala evolutiva (CAVALIER-SMITH, 1985 a, CAVALIER-SMITH, 1985 b). Por exemplo, por que os anfíbios, de maneira geral, possuem muito mais DNA nuclear do que os mamíferos, e por que as samambaias apresentam valores tão altos de DNA quando comparadas com as angiospermas, que são as plantas mais evoluídas?

Muitas explicações surgiram para o paradoxo-C, como as do DNA fisiologicamente inerte, DNA "lixo", DNA carregado passivamente pelos cromossomos apenas por estar ligado a genes funcionais, DNA parasita ou egoísta, DNA com funções não gênicas, entre outras (CAVALIER-SMITH, 1985 a).

Nas angiospermas, os valores $\mathrm{C}$ variam até 600 vezes, de menos de 0.2pg em Arabidopsis thaliana a 127, 4pg em Fritillaria assyriaca (BENNET \& LEITCH, 1997). Dentro de um mesmo gênero de plantas, a quantidade de DNA pode variar, e essa variação muitas vezes está associada e é explicada pela poliploidia, presença de heterocromatina ou cromossomos extranumerários (REES, 1972). Por outro lado, mesmo entre espécies de mesmo nível de ploidia pode haver variação na quantidade de DNA nuclear, como por exemplo de três vezes entre as espécies diplóides de Lathyrus (NARAYAN \& REES, 1976, 1977), e até seis vezes entre as espécies diplóides de Vicia (CHOOI, 1971).

Porém, a quantidade de DNA dentro de uma espécie e dentro de um mesmo indivíduo (ressalvadas as condições acima, além da presença, em um mesmo organismo, de células com diferentes níveis de ploidia) é aceita como constante. $\mathrm{O}$ valor $\mathrm{C}$ define a quantidade de DNA do genoma haplóide, não replicado, de um indivíduo. A quantidade de DNA é expressa em picogramas (pg), $10^{-12} \mathrm{~g}$ ou em mega pares de bases de nucleotídeos $\left(\mathrm{Mb}=10^{6}\right.$ pares de bases), sendo que $1 \mathrm{pg}$ corresponde a $965 \mathrm{Mb}$ (BENNET \& LEITCH, 1995). BENNET \& LEITCH (1997) citam alguns dados isolados que indicam alterações na quantidade de DNA influenciada por fatores ambientais, mas salientam a necessidade de repetições e amplas discussões sobre o assunto, o que poderia desafiar o conceito da constância do valor $\mathrm{C}$.

\section{POR QUE DETERMINAR A QUANTIDADE DE DNA NUCLEAR}

$\mathrm{O}$ valor $\mathrm{C}$ de DNA é um caráter de significado biológico fundamental e o conhecimento da quantidade de DNA nuclear de um grupo de organismos pode ser útil em vários campos, como biologia molecular e celular, ecologia, fitogeografia e sistemática (BENNET \& LEITCH, 1995).

Do ponto de vista prático, a determinação da quantidade de DNA nuclear pode substituir a contagem de cromossomos, especialmente quando se trabalha com um número muito grande de indivíduos, como por exemplo em bancos de germoplasma. O conhecimento do número de cromossomos, ou do nível de ploidia, além de importantíssimo para a caracterização do germoplasma é imprescindível para os trabalhos de melhoramento genético, quando são programados cruzamentos. A determinação do número de cromossomos, apesar de ser uma técnica relativamente simples, demanda tempo. Sua substituição por uma técnica mais expedita, que dê um resultado semelhante, ou seja, indique o nível de ploidia com um grau aceitável de precisão permite agilizar uma série de trabalhos, seja de manutenção de germoplasma, seja de seleção, nas progênies de cruzamentos, de indivíduos com os níveis de ploidia desejados.

Para as angiospermas, listagens de todas as informações de determinações de quantidade de DNA nuclear, na medida em que são realizadas, têm sido periodicamente publicadas (BENNET \& SMITH, 1976; BENNET et al., 1982; BENNET \& LEITCH, 1995; BENNET \& LEITCH,1997; BENNET \& LEITCH, 2000). Atualmente, a quantidade de DNA nuclear é conhecida para menos de 3000 espécies de angiospermas, o que representa apenas $1 \%$ da flora mundial deste grupo de plantas (BENNET \& LEITCH, 1997). As informações atualizadas também podem ser consultadas pela rede, em http://www.rbgkew.org.uk/cval/database1.html (BENNET \& LEITCH, 1997). 


\section{COMO SE DETERMINA A QUANTIDADE DE DNA NUCLEAR}

A determinação da quantidade de DNA nuclear pode ser realizada basicamente por meios químicos, cinética de reassociação microdensitometria e citometria de fluxo. Os meios químicos e de cinética de reassociação, são bastante precisos, mas trabalhosos e demorados, envolvem extração de DNA e seu uso atualmente é muito restrito. (BENNET \& LEITCH, 1995).

A técnica desenvolvida em torno de 1960, de microdensitometria por Feulgen baseia-se na ligação específica do DNA ao corante Feulgen (ou reagente de Schiff), descrita em 1924 por Feulgen \& Rössenbeck (BENNET \& SMITH, 1976). Como o DNA não possui um cromóforo natural na amplitude da luz visível, um corante exógeno deve ser associado à molécula. A coloração de Feulgen é específica para o DNA, após o RNA ter sido removido por hidrólise ácida, e há uma proporcionalidade entre a quantidade de DNA e a quantidade de corante que o núcleo incorporou. A absorção de luz por um núcleo corado será uma medida quantitativa do DNA presente, (Mc LEISH \& SUNDERLAND, 1961; BERLIN \& CECICH, 1976). Para medir o DNA através da microdensitometria de Feulgen, utilizamse as técnicas de leitura ótica com um ou dois comprimentos de onda, sendo um dos comprimentos de onda aquele em que há o pico máximo de absorção de luz visível pelo DNA (entre 550 e 570nm) e o outro no qual há $50 \%$ da absorção máxima (em torno de 490nm). A absorção de luz sempre é comparada com a área do citoplasma ao redor. Os equipamentos iniciais constituíam-se em um microscópio equipado com um espectrofotômetro e um densitômetro. Mais tarde, foram desenvolvidos, especificamente para esta técnica, microdensitômetros de integração. São necessários cuidados na preparação das amostras, desde aspectos simples como o tempo de hidrólise, tipo de tecido, utilização de um mesmo padrão de conteúdo de DNA conhecido. O método, para ser preciso, deve ser cuidadosamente padronizado (BENNET \& SMITH, 1976). Os dados conflitantes, de diferentes autores, que aparecem na literatura para alguns casos são, quase sempre, causados por problemas técnicos. Alguns pontos cruciais nestas determinações são a medição de núcleos com o mesmo nível de ploidia e utilização de um padrão, cuja quantidade precisa de DNA tenha sido determinada por meios bioquímicos. Como padrões são frequentemente utilizados eritróctos de galinha, leucócitos humanos, cultivares específicos de Vicia faba, Allium cepa, Triticum aestivum, entre outros.
Como alguns exemplos de determinações de DNA nuclear em plantas por microdensitometria de Feulgen, podem-se citar aqueles em Allium (JONES \& REES, 1968; OHRI et al., 1998), Aegilops (FURUTA, 1975; FURUTA et al., 1975), Crepis (WALLACE et al., 1972), Gossypium (EDWARDS et al., 1974; EDWARDS \& ENDRIZZI, 1975), Picea e Pinus (TEOH \& REES, 1976), Alopecurus (SIEBER \& MURRAY, 1979), Vicia (CHOOI, 1971; CREMONINI et al., 1993, 1998), Scilla (GREILHUBER, 1977, 1978), Lolium (GUPTA \& REES, 1975), Leucanthemun (MARCHI et al., 1983), Briza (MURRAY, 1975; SCHIFINO \& WINGE, 1983), Prospero (EBERT et al., 1996), entre muitos outros.

A citometria de fluxo foi inicialmente desenvolvida para contagem e análise rápidas de células sangüíneas. A partir da década de 80 começou a ser adaptada para células vegetais (DOLEZEL, 1997). Esta técnica envolve a análise das propriedades óticas de partículas em fluxo, movendo-se em relação ao ponto de medida. As partículas estão hidrodinamicamente contidas no centro de um fluxo estreito de líquido e passam por um foco de luz intensa, o que permite a excitação dos fluorocromos presentes nas partículas. Os pulsos de luz e de fluorescência são colhidos por um sistema de detecção ótica, separados por filtro e convertidos em pulsos elétricos por sensores óticos (DOLEZEL, 1997). Em plantas, basicamente consiste no isolamento dos núcleos (em geral de tecido foliar), coloração com um fluorocromo e leitura da fluorescência emitida por estes núcleos em um citômetro de fluxo. A fluorescência é proporcional ao conteúdo de DNA. Em geral são necessários 10000 núcleos, o que equivale a cerca de $50 \mathrm{mg}$ de tecidos. Um padrão interno, isto é, um material cuja quantidade de DNA é conhecida com certeza, permite que os valores relativos sejam convertidos em valores absolutos. Normalmente são verificados dois picos de fluorescência, aquele dos núcleos $2 \mathrm{C}$ (células em G0 e G1) e aquele dos núcleos 4C (células em G2 e mitose). Os tipos de fluorocromos mais empregados são o DAPI (diamidino2-fenilindol), PI (iodeto de propídio) e EB (brometo de etídio), em concentrações variáveis ( em torno de $\left.50 \mu \mathrm{gml}^{-1}\right)($ BENNET \& LEITCH, 1995).

As grandes vantagens desta técnica, em relação à microdensitometria de Feulgen, são a relativa facilidade e a rapidez da preparação das amostras, a possibilidade de análise de um grande número de núcleos, que não necessitam ser núcleos em divisão, o que permite que praticamente qualquer tecido seja utilizado, e em pequenas quantidades, e a possibilidade de detecção de pequenas diferenças na quantidade de DNA (BENNET \& LEITCH, 1995). 
Entretanto, sua utilização não aumentou grandemente o número de novas determinações de DNA nuclear em plantas e os valores conflitantes encontrados entre diferentes determinações, além do custo do equipamento, não contribuem para tornar a técnica tão amplamente difundida como seria de esperar (BENNET \& LEITCH, 1995). Há necessidade de muito cuidado na aplicação da técnica, para que sua sensibilidade e praticidade possa ser acompanhada pela precisão.

De acordo com DOLEZEL (1997), a citometria de fluxo pode ser útil no melhoramento de plantas para controlar a estabilidade do nível de ploidia, identificar haplóides e duplohaplóides em culturas de anteras e ovários, verificar novos níveis de ploidia em resultados de cruzamentos, detecção de aneuplóides, no estudo da apomixia, identificação do sexo em plantas dióicas, identificação de híbridos, identificação de polisomatia, acompanhamento do desenvolvimento da semente, identificação do produto de fusão de protoplastos. A análise do nível de ploidia é atualmente a aplicação mais comum da citometria de fluxo no melhoramento genético e produção de sementes.

Como alguns exemplos de trabalhos utilizando a citometria de fluxo para determinar a quantidade de DNA em plantas, podem-se citar aqueles com Lathyrus (MURRAY et al., 1992; NANDINI et al., 1997), Prunus (BAIRD et al., 1994), Leucaena (PALOMINO et al., 1995), Eleusine (MYSORE \& BAIRD, 1997), Pennisetum (MARTEL et al., 1997), Salix (THIBAULT, 1998), Hypochaeris (CERBAH et al., 1999), Musa (LYSÁK et al., 1999), Crepis (DIMITROVA \& GREILHUBER, 2000), entre muitos outros.

Quando os trabalhos são realizados em condições controladas e pelos mesmos pesquisadores, os resultados obtidos pela microdensitometria de Feulgen e pela citometria de fluxo são comparáveis (GREILHUBER \& OBERMAYER, 1998; BARANYI \& GREILHUBER, 1999; DIMITROVA et al., 1999; DIMITROVA \& GREILHUBER, 2000).

\section{VARIAÇÃO INTRAESPECÍFICA NA QUAN- TIDADE DE DNA NUCLEAR: REALIDADE OU PROBLEMA TÉCNICO?}

Quando os resultados de determinações de DNA nuclear por diferentes autores, para as mesmas plantas, são comparados, frequentemente verificam-se diferenças discrepantes entre os resultados, como pode ser visto consultando-se listagens como as de BENNET \& SMITH (1976) e BENNET
\& LEITCH (1995), BENNET \& LEITCH (1997) e BENNET \& LEITCH (2000).

As explicações aventadas são de dois tipos: que as diferenças intraespecíficas no conteúdo de DNA nuclear são reais, ou seja, de que a quantidade de DNA nuclear não é necessariamente estável dentro de uma determinada espécie; ou de que estas diferenças são causadas por problemas técnicos. Ainda permanece a dúvida se as variações relatadas refletem uma plasticidade do genoma nuclear ou se são devidas a erros metodológicos.

Por exemplo, LYSÁK et al. (1999) verificaram diferenças pequenas mas estatisticamente significativas entre subespécies e clones de $\boldsymbol{M}$. $\boldsymbol{a c u}$ minata. NANDINI et al. (1997) relataram diferenças intraespecíficas significantes na quantidade de DNA nuclear para duas espécies de Lathyrus.

Por outro lado, muitos destes dados discordantes são realmente problemas técnicos, como ajuste do aparelho, tipo de flurocromo usado, condições ambientais do laboratório, condições de preparo da amostra e padrão utilizado. GREILHUBER \& EBERT (1994) e GREILHUBER \& OBERMAYER (1997) demonstraram que as variações intraespecíficas relatadas para Pisum sativum e Cajanus cajan, respectivamente, eram causadas por problemas metodológicos. Da mesma forma, BARANYI \& GREILHUBER (1999), realizando uma criteriosa comparação de diversas publicações sobre o tamanho do genoma em Allium, concluíram que as discrepâncias observadas entre os diferentes autores devem-se com altíssima probabilidade às condições experimentais e enfatizam a necessidade, reconhecida atualmente pela maioria dos pesquisadores, de melhorias na padronização e nos procedimentos técnicos para as determinações do tamanho do genoma.

\section{CONCLUSÕES E PERSPECTIVAS}

Considerando o custo da citometria de fluxo, quando comparada com a técnica de Feulgen, e analisando os relatos recentemente publicados com uma e outra técnica, BENNET \& LEITCH (1995) e BENNET \& LEITCH (1997) consideram que, apesar de seu potencial, é pouco provável que a citometria de fluxo vá, a curto prazo, substituir a microdensitometria de Feulgen para estimar os valores $\mathrm{C}$ de DNA, e que a técnica de Feulgen provavelmente continuará sendo a mais empregada em países em desenvolvimento.

Porém, a utilização da citometria de fluxo para determinação da quantidade de DNA é um avanço e uma contribuição importantíssima tanto para estudos mais acadêmicos como também para o 
melhoramento genético, especialmente no manejo de grandes coleções de germoplasma e no controle dos níveis de ploidia em resultados de cruzamentos. Sem ela, a rapidez do trabalho pode ficar comprometida, pois o número de indivíduos analisados será muito pequeno. Alguns cuidados básicos são essenciais, como calibragem freqüente do aparelho, comparação de materiais com número cromossômico determinado e valores de DNA conhecidos, manutenção e checagem periódica do padrão e padronização cuidadosa dos procedimentos.

Na dúvida quanto ao nível exato de ploidia, não se deve esquecer que a confecção de uma simples lâmina de ponta de raiz ou célula-mãe-depólen, para contagem do número de cromossomos, pode facilmente resolver o problema e ainda é a solução mais segura.

\section{REFERÊNCIAS BIBLIOGRÁFICAS}

BAIRD, W.V., ESTAGER, A.S., WELLS, J.K. Estimating nuclear DNA content in peach and related diploid species using laser flow cytometry and DNA hybridization. Journal of the American Society of Horticultural Science, Alexandria, v.119, p.1312-1316, 1994.

BARANYI, M., GREILHUBER, J. Genome size in Allium: in quest of reproducible data. Annals of Botany, Bristol, v.83, p.687-695, 1999

BENNET, M.D. The duration of meiosis. Proceedings of the Royal Societ of London B, London, v.178, p.259-275, 1971.

BENNET, M.D. Nuclear DNA content and minimum generation time in herbaceous plants. Proceedings of the Royal Societ of London B, London, v.181, p.109-135, 1972.

BENNET, M.D., SMITH, J.B. Nuclear DNA amounts in angiosperms. Philosophical Transactions of the Royal Society of London B, London, v.274, p.227-274, 1976.

BENNET, M.D., LEITCH, I.J. Nuclear DNA amounts in angiosperms. Annals of Botany, Bristol, v.76, p.113-176, 1995.

BENNET, M.D., LEITCH, I.J. Nuclear DNA amounts in angiosperms - 583 new estimates. Annals of Botany, Bristol, v.80, p.169-196, 1997

BENNET, M.D., LEITCH, I.J. Nuclear DNA amounts in angiosperms and their modern uses - 807 new estimates. Annals of Botany, Bristol, v.86, p.859-909, 2000.

BENNET, M.D., SMITH, J.B., HESLOP-HARRISON, J.S. Nuclear DNA amounts in angiosperms. Proceedings of the Royal Society of London B, London, v.216, p.179-199, 1982.

BERLYN, G.P., CECICH, R.A. Optcial techniques for measuring DNA quantities. In: MIKSCHE, J.P. Modern methods in forest genetics. New York : Springer, 1976. p.1-18.

CAVALIER-SMITH, T. Eukaryote gene numbers, non-coding DNA and genome size. In: CAVALIER SMITH, T. The evolution of genome size. Chichester : John Wiley \& Sons, 1985a. p.1-36.

CAVALIER-SMITH, T. Introduction: the evolutionary significance of genome size. In: CAVALIER SMITH, T. The evolution of genome size. Chichester : John Wiley \& Sons,1985b. p.69-103.

CERBAH, M., COULAUD, J., BROWN, S.C., et al. Evolutionary DNA variation in the genus Hypochaeris. Heredity, Essex, v.82, p.261-266, 1999

CHOOI, W.Y. Variation in nuclear DNA content in the genus Vicia. Genetics, Pittsburgh, v.68, p.195-211, 1971.

CREMONINI, R., FUNARI, S., GALASSO, I., et al. Cytology of Vicia species II. Banding patterns and chromatin organization in Vicia atropurpurea Desv. Heredity, Essex, v.70, p.628-633, 1993.

CREMONINI, R., CASTIGLIONI, M.R., VENORA, G. et al. Cytology of Vicia species. VI. Nuclear chromatin organization, karyomorphological analysis and DNA amount in Vicia serratifolia Jacq. Caryologia, Firenze, v.51, p.19520, 1998.

DIMITROVA, D., EBERT, I., GREILHUBER, T., $\boldsymbol{e} \boldsymbol{t} \boldsymbol{a l}$. Karyotype constancy and genome size variation in Bulgarian Crepis foetida s.l. (Asteraceae). Plant Systematics and Evolution, Vienna, v.217, p.245-257, 1999.

DIMITROVA, D., GREILHUBER, J. Karyotype and DNAcontent evolution in ten species of Crepis (Asteraceae) distributed in Bulgaria. Botanical Journal of the Linnen Society of London, London, v.132, p.281-197, 2000.

DOLEZEL, J. Flow cytometry, its application and potential for plant breeding. In: LELLEY, T. Current topics in plant cytogenetics related to plant improvement. Vienna: WUV-Universitätsverlag, 1997. p.80-90

EBERT, I., GREILHUBER, J., SPETA, F. Chromosome banding and genome size differentiation in Prospero (Hyacinthaceae) diploids. Plant Systematics and Evolution, Vienna, v.203, p.143-177, 1996

EDWARDS, G.A., ENDRIZZI, J.E. Cell size, nuclear size and DNA content relationships in Gossypium. Canadian Journal of Genetics and Cytology, Ottawa, v.17, p.181-186, 1975.

EDWARDS, G.A., ENDRIZZI, J.E., STEIN, R. Genome DNA content and chromosome organization in Gossypium. Chromosoma, Berlin, v.47, p.309-326, 1974.

FURUTA, Y. Quantitative variation of nuclear DNA in genus Aegilops. Japanese Journal of Genetics, Tokyo, v.50, p.383-392, 1975.

FURUTA, Y., NISHIKAWA, K., MAKINO, T. Intraspecific variation of nuclear DNA content in Aegilops squarrosa L. Japanese Journal of Genetics, Tokyo, v.50, p.257-263, 1975.

GREILHUBER, J. Nuclear DNA and heterochromatin contents in the Scilla hohenackeri group, S. persica and Puschkinia scilloides (Liliaceae). Plant Systematics and Evolution, Vienna, v.128, p.243-257, 1977

GREILHUBER, J. DNA contents, Giemsa banding,and systematics in Scilla bifolia, S. drunensis and $S$.

Ciência Rural, v. 31, n. 5, 2001. 
vindobonensis (Liliaceae). Plant Systematics and Evolution, Vienna, v.130, p.223- 233, 1978.

GREILHUBer, J., EBERT, I. Genome size variation in Pisum sativum. Genome, Ottawa, v.37, pp. 646-655, 1994.

GREILHUBER, J., OBERMAYER, R. Genome size variation in Cajanus cajan (Fabaceae): a reconsideration. Plant Systematics and Evolution, Vienna, v.212, p.135-141, 1998.

GUPTA, P.K., REES, H. Tolerance of Lolium hybrids to quantitative variation in nuclear DNA. Nature, London, v. 257, p.587-588, 1975

JONES, R.N., REES, H. Nuclear DNA variation in Allium. Heredity, Essex, v.23, p.591-605, 1968.

LYZAK, M.A., DOLEZELOVA, M., HORRY, J.P., et al. Flow cytometric analysis of nuclear DNA content in Musa. Theoretical and Applied Genetics, Berlin, v.98, p.1344$1350,1999$.

MARCHI, P., ILLUMINATI, O., MACIOCE, A., et al. Genome evolution and polyploidy in Leucanthemum vulgare Lam. aggr. (Compositae). Karyotype analysis and DNA microdensitometry. Caryologia, Firenze, v.36, p.1-18, 1983.

MARTEL, E., DE NAY, D., SILJAK-YAKOVLEV, S. $\boldsymbol{e}$ t al. Genome size variation and basic chromosome number in pearl millet and fourteen related Pennisetum species. Journal of Heredity, Washington, v.88: 139-143, 1997.

McLEISH, J., SUNDERLAND, N. Measurements of deoxyribosenucleic acid (DNA) in higher plants by Feulgen photometry and chemical methods. Experimental Cell Research, San Diego, v.24, p.527-540, 1961.

MURRAY, B.G. The cytology of the genus Briza L (Gramineae). I. Chromosome numbers, karyotypes and nuclear DNA variation. Chromosoma, Berlin, v.49, p.299$308,1975$.

MURRAY, B.G., HAMMET, K.R.W., STANDRING, L.S Genomic constancy during the development of Lathyrus odoratus cultivars. Heredity, Essex, v.68, p.321-327, 1992.

MYSORE, K.S., BAIRD, V. Nuclear DNA content in species of Eleusine (Gramineae): a critical re-evaluation using laser flow cytometry. Plant Systematics and Evolution, Vienna, v.207, p.1-11, 1997.
NANDINI, A.V., MURRAY, B.G., O'BRIEN, I.E.W., et $\boldsymbol{a}$ l. Intra- and interspecific variation in genome size in Lathyrus (Leguminosae). Botanical Journal of the Linnean Society of London, London, v.125, p.359-366, 1997.

NARAYAN, R.K., REES, H. Nuclear DNA divergence among Lathyrus species. Chromosoma, Berlin, v.63, p.101-107, 1977.

NARAYAN, R.K., REES, H. Nuclear DNA variation in Lathyrus. Chromosoma, Berlin, v.54: 141-154, 1976.

OHRI, D., FRITSCH, R.M., HANELT, P. Evolution of genome size in Allium (Alliaceae). Plant Systematics and Evolution, Vienna, v.210, p.57-86, 1998.

PALOMINO, G., ROMO, G., ZÁRATE. S. Chromosome numbers and DNA content in some taxa of Leucaena (Fabaceae Mimosoideae). Cytologia, Tokyo, v.60, p.31-37, 1995.

REES, H., JONES, R.N. The origin of the wide species variation in nuclear DNA content. International Review of Cytology, San Diego, v.32, p.53-92, 1972.

REES, H. DNA in higher plants. In: BROOKHAVEN SYMPOSIUM BIOLOGY, 1972, Brookhaven. Proceedings... Brookhaven : Genetics Society of America, 1972. v.23, p.394-418.

SCHIFINO, M.T., WINGE, H. Karyotypes and nuclear DNA content of species of the Briza complex and some other genera of Poeae (Gramineae). Revista Brasileira de Genética, Ribeirão Preto, v.6, p.245-259, 1983.

SIEBER, V.K., MURRAY, B.G. The cytology of the genus Alopecurus (Gramineae). Botanical Journal of the Linnean Society of London, London, v.29, p.343-355, 1979.

TEOH, S.B., REES, H. Nuclear DNA amounts in populations of Picea and Pinus species. Heredity, Essex, v.36, p.123-137, 1976.

THIBAULT, J. Nuclear DNA amount in pure species and hybrid willows (Salix): a flow cytometric investigation. Canadian Journal of Botany, Ottawa, v.76, p.157-165, 1998.

WALLACE, H., SPARKES, C.A., MADEN, M. Nuclear DNA content of three Crepis species. Heredity, Essex, v.29, p.367-373, 1972 .

Ciência Rural, v. 31, n. 5, 2001. 